\title{
Development of Alginate-Montmorillonite-Starch with Encapsulated Trichoderma harzianum and Evaluation of Conidia Shelf Life
}

\author{
Fariz Adzmi $^{1 *}$, Mohamed Hanafi Musa ${ }^{2}$, Yasmeen Siddiqui ${ }^{3}$, Wong Mui Yun ${ }^{3}$, Hazandy Abdul Hamid ${ }^{4,5}$, Arifin Abdu ${ }^{5}$ \\ and Rambod Abiri ${ }^{5}$ \\ ${ }^{1}$ Laboratory of Plantation Science and Technology, Institute of Plantation Studies, Universiti Putra Malaysia, 43400 Serdang, \\ Selangor, Malaysia \\ ${ }^{2}$ Department of Land Management, Faculty of Agriculture, Universiti Putra Malaysia, 43400 Serdang, Selangor, Malaysia \\ ${ }^{3}$ Laboratory of Sustainable Agronomy and Crop Protection, Institute of Plantation Studies, Universiti Putra Malaysia, 43400 \\ Serdang, Selangor, Malaysia \\ ${ }^{4}$ Laboratory of Bioresource Management, Institute of Tropical Forestry and Forest Product, Universiti Putra Malaysia, \\ 43400 Serdang, Selangor, Malaysia \\ ${ }^{5}$ Department of Forestry Science and Biodiversity, Faculty of Forestry and Environment, Universiti Putra Malaysia, 43400 \\ Serdang, Selangor, Malaysia
}

*For correspondence: farizadzmi@upm.edu.my

Received 04 December 2020; Accepted 08 March 2021; Published 10 June 2021

\begin{abstract}
Biological control agents, such as Trichoderma harzianum, are widely used in sustainable agriculture. However, commercialisation and mass production of biocontrol products have remained a challenge, especially in viability and efficiency in field application. The encapsulation method has emerged as a sophisticated technique to develop the formulation of $T$. harzianum. Hence, encapsulation through extrusion was used to prepare $T$. harzianum beads. The physical characteristics comprising weight, diameter, and swelling ability of the beads were significantly improved when the starch percentage was increased. Alginate-montmorillonite-starch (10\%) revealed the lowest shrinkage and the highest swelling ability. The interaction within the functional groups of alginate, montmorillonite, and starch was confirmed by the Fourier-transform infrared spectroscopic (FTIR) study. Furthermore, scanning electron microscopic analysis exposed compatible scattering of montmorillonite particles and starch granules over the alginate linkages. Meanwhile, the X-ray diffraction analysis confirmed the exfoliation between starch and montmorillonite. Storage of $T$. harzianum beads at $5^{\circ} \mathrm{C}$ was more suitable than storage at $28^{\circ} \mathrm{C}$. At low temperature, the encapsulated $T$. harzianum beads maintained their viability at $6.59 \pm 0.12 \log \mathrm{CFU} \mathrm{g}^{-1}$ for an effective threshold value for up to seven months. The current findings indicated that the combination of alginate, montmorillonite, and starch is the best formulation of encapsulated T. harzianum with improved conidia shelf life. (C) 2021 Friends Science Publishers
\end{abstract}

Keywords: Alginate-montmorillonite-starch; Biological control agents; Encapsulation; Extrusion; Shelf life; Trichoderma harzianum

\section{Introduction}

Sustainable agriculture practices emphasise environmental friendliness to adopt new sustainable methods, such as using microorganisms as biological control agents (BCAs) to control plant pathogens (Curtis et al. 2010). The BCAs have emerged as one of the preferred management strategies to reducing yield loss and is innocuous to human beings (Lecomte et al. 2016). The biggest challenges for BCAs to be competitive in the market than chemical fungicides are consistency, effectiveness, and shelf life. These issues can be solved through scientific development in formulating 'BCAs (Kumar et al. 2019).
Encapsulation is emerging as a sophisticated technology for the formulation of BCAs. The advantages of encapsulation include significantly prolonged shelf life of BCAs by offering protection or stabilisation from biotic and abiotic stress factors, such as soil antagonists, contaminations, temperature, dryness, and ultraviolet (UV) light; or from mechanical stress by altering physical properties and providing a beneficial microenvironment (Rathore et al. 2013). This technology helps to maintain the metabolic activity of BCAs for an extended period during storage and after application (Szczech and Maciorowski 2016). Another important feature of encapsulation is the controlled release of the entrapped cells or spores (He et al.

To cite this paper: Adzmi F, MH Musa, Y Siddiqui, WM Yun, HA Hamid, A Abdu, R Abiri (2021). Development of alginate-montmorillonite-starch with encapsulated Trichoderma harzianum and evaluation of conidia shelf life. Intl J Agric Biol 26:87-96 
2015), where they can be released by the factor of osmosis from the bead matrixor by the degradation of the encapsulation material. The released cells or spores can survive longer in the soil or with extended persistence, resulting in fewer applications and doses (Schoebitz et al. 2012; Ma et al. 2015). The choice of carrier for the encapsulation matrix is an important factor determining the success of BCA encapsulation.

Generally, biodegradable polymer materials, specifically natural polysaccharides such as alginate, gum, $k$ carrageenan, and agar, are used as a matrix (Vemmer and Patel 2013). Among these compounds, alginate is most preferred for carrier encapsulation. It is originally from brown seaweed that consists of linear unbranched polymers $\beta$ - $(1 \rightarrow 4)$-linked D-mannuronic acid $(\mathrm{M})$ and $\gamma$ - $(1 \rightarrow 4)$-linked L-guluronic acid $(\mathrm{G})$ residues (Tavassoli-Kafrani et al. 2016). The characteristics of alginate, such as biodegradability, nontoxicity, biocompatibility, and ease of gelation with various cross-linking agents, render it a preferred carrier material for BCAs (Tam et al. 2011; Simó et al. 2017). However, like other hydrogels, the limitations of alginate include mechanical stiffness, distorted shape, varying size, and poor physical properties that make it unsuitable for providing long-term stability of the encapsulated cells (Sriamornsak et al. 2017; Rodrigues et al. 2020).

Thus, to overcome these limitations, suitable filler is usually added to the formulation. It could be soluble, insoluble, or a combination of both. Fillers, such as montmorillonite and starch, were used to formulate encapsulated beads (Mohammadi et al. 2019). Montmorillonite is a three-layered mineral consisting of two tetrahedral layers sandwiched around a central octahedral layer (Itadani et al. 2017). It has several advantages, e.g., high cation exchange capacity, large surface area, excellent swelling ability, and is naturally present in soils, making montmorillonite a suitable filler encapsulation (Chevillard $e t$ al. 2012). Meanwhile, starch is a biodegradable polysaccharide, cheap and easily available (Riyajan 2017). The incorporation of fillers attracts great attention because of the noticeable improvements in the physical properties of the beads when loading is only between $1 \%$ and $3 \%$ (Fernandez-Perez et al. 2004). Moreover, fillers act as core substructure to curb shrinkage and result in the shape of the beads during the dehydration process (Singh et al. 2009).

Trichoderma harzianum has a wide spectrum of antimicrobial activity. Depending on the strain, Trichoderma is known to (i) colonise the rhizosphere (rhizosphere competence) and concede acceleration establishment in the substantial microbial environment around the rhizosphere; (ii) restrain plant pathogens through diverse mechanisms (Ali et al. 2020; Khan et al. 2021); (iii) enhance plant growth (Javaid et al. 2021); and (iv) control root growth (Soresh and Harman 2008). Generally, their efficacy in the field is restricted due to the factors above. Therefore, this study was performed to encapsulate $T$. harzianum in alginate, montmorillonite, and starch formulation. The aims were to improve the physical properties and characterise chemical interaction of the materials used in the encapsulation formulation, and concurrently study the shelf life of the T. harzianum beads.

\section{Materials and Methods}

\section{Encapsulation of $T$. harzianum in alginate- montmorillonite-starch beads}

T. harzianum (UPMC 243) was obtained from the Microbial Culture Collection Unit at the Institute of Bioscience, Universiti Putra Malaysia. Twenty-five culture plates of $T$. harzianum were maintained on the potato dextrose agar (Becton, Dickinson and Company, USA) media at $28 \pm 2{ }^{\circ} \mathrm{C}$. To get the conidial pellet, $10 \mathrm{~mL}$ of sterile distilled water was added into each of the seven-day-old $T$. harzianum culture plates, and the surface was scraped gently with a sterilised bent glass rod. The conidial suspension was centrifuged at $7000 \mathrm{rpm}$ for $10 \mathrm{~min}$ (Wijesinghe et al. 2011), and the beads were prepared using the extrusion technique (Raha et al. 2018). Accordingly, $2.5 \mathrm{~g}(1 \% \mathrm{w} / \mathrm{v})$ of montmorillonite (K 10, Sigma-Aldrich) and $2.5 \mathrm{~g}(1 \%$ w/v) of starch (Becton, Dickinson and Company, U.S.A.) were dispersed together in $250 \mathrm{~mL}$ sterile distilled water and stirred for $24 \mathrm{~h}$ to form a homogenous solution. Then, $5 \mathrm{~g}$ $(2 \% \mathrm{w} / \mathrm{v})$ of alginate powder (Sigma-Aldrich) was added to the starch and montmorillonite solution and stirred for $2 \mathrm{~h}$ using a magnetic stirrer (Heidolph, Germany). Subsequently, $T$. harzianum conidial pellets were added to the mixture with continuous stirring for another $4 \mathrm{~h}$ to give a conidial concentration of $1.3 \times 10^{11} \mathrm{~mL}^{-1}$. Finally, the mixture was dropped through a $10 \mathrm{~mL}$ pipette tip from a 15 cm height into $0.5 \mathrm{M} \mathrm{CaCl}_{2}$ (Sigma-Aldrich) under constant stirring for gelation. After $2 \mathrm{~h}$, the beads were taken out of the $\mathrm{CaCl}_{2}$ solution by sieving and washed several times with distilled water. The beads were then allowed to dry at room temperature for $24 \mathrm{~h}$. The experiment was performed in a similar manner using 3\%, 5\%, and $10 \%(\mathrm{w} / \mathrm{v})$ of starch, with a fixed amount of $2 \%$ alginateand $1 \%$ montmorillonite (Bokkhim et al. 2016).

\section{Physical characterisation}

In total, 20 beads were measured, with five beads sampled randomly from each treatment (varying concentrations of starch). The weight of the beads was measured using a digital balance (Mettler Toledo, Switzerland) and expressed in milligrams $(\mathrm{mg})$. The diameter of the beads was measured using a stereomicroscope (Leica Microsystems, Germany), and the bead shape was calculated using a sphericity factor (SF) (Chan et al. 2011a):

$$
S F=\left(\frac{d \max -d \min }{d \max +d \min }\right) \times 100
$$

Where, $d_{\max }$ is the largest diameter and $d_{\min }$ is the smallest diameter of the beads. 
Shrinkage of encapsulated beads was determined using the following equation:

$$
\text { Shrinkage }(\%)=\left(\frac{D_{w}-D_{d}}{D_{w}}\right) \times 100
$$

Where, $D_{\mathrm{w}}$ is the diameter of the wet beads and $D_{\mathrm{d}}$ is the diameter of the dry beads.

The swelling capacity or ability of the encapsulated beads was measured by suspending 20 dried beads from each concentration of starch in $10 \mathrm{~mL}$ of distilled water with five replicates under mild shaking for $24 \mathrm{~h}$. The swollen beads were removed and pressed between two filter papers to remove the excess water and weighed on a digital balance. The swelling percentage was calculated using the following equation (Dai et al. 2019):

$$
\text { Swelling }(\%)=\frac{\left(W_{s}-W_{d}\right)}{W_{d}} \times 100
$$

Where, $W_{\mathrm{s}}$ and $W_{\mathrm{d}}$ are the weights of the swollen and dry beads, respectively.

\section{Chemical characterisation}

Alginate-montmorillonite-starch (10\%) was chosen for chemical characterisation. The assessment was conducted using an FTIR spectrophotometer (Perkin Elmer 1650, U.S.A) via the $\mathrm{KBr}$ disc method. Each sample was pulverised, gently triturated with $\mathrm{KBr}$ powder at a weight ratio of 1:100, and then pressed using a hydrostatic press at 10 tons for $5 \mathrm{~min}$. The disc was placed in the sample holder and scanned from 4000 to $400 \mathrm{~cm}^{-1}$ at a resolution of 4 $\mathrm{cm}^{-1}$. The internal morphology of the encapsulated beads was analysed using a scanning electron microscope (SEM; JEOL, U.S.A. and Leo 1455, Germany) at 1000× magnification. The X-ray diffraction (XRD) analysis was recorded using an XRD diffractometer (Siemens D-5000, U.S.A.) with $\mathrm{Cu} \mathrm{K \alpha}(\lambda=1.5418 \AA)$ radiation at $40 \mathrm{kV}$ and $40 \mathrm{~mA}$ (Pawar et al. 2018).

\section{Entrapment efficacy, conidia release, and stability of $T$. harzianum beads}

A total of ten individual $T$. harzianum beads were taken from each starch concentration. The beads were mashed using a sterile mortar and pestle. An amount of $10 \mathrm{~mL}$ sterile distilled water was added to the resulting powder from the encapsulated beads. Serial dilutions were made, and $0.1 \mathrm{~mL}$ aliquots were plated on rose Bengal agar media, where all plates were incubated at $28 \pm 2{ }^{\circ} \mathrm{C}$. The number of colonies formed after four days of incubation was recorded as colony-forming units (CFU) per encapsulated bead. The plate count was conducted in five replicates, where the average was considered the final value of CFU per $T$. harzianum encapsulated beads.

Conidial release of $T$. harzianum encapsulated beads over time were determined by suspending $100 \mathrm{mg}$ of $T$. harzianum beads in $10 \mathrm{~mL}$ sterile distilled water followed by incubation for $2 \mathrm{~h}$ with mild agitation at $160 \mathrm{rpm}$. Serial dilutions of the suspension were made, and $0.1 \mathrm{~mL}$ aliquots were plated on a rose Bengal medium, followed by incubation at $28 \pm 2{ }^{\circ} \mathrm{C}$. The number of colonies formed after four days of incubation was recorded as CFU $\mathrm{g}^{-1}$ and expressed as $\log \mathrm{CFU} \mathrm{\textrm {g } ^ { - 1 }}$ of encapsulated beads. The plate count was conducted in five replicates. The final value of CFU $\mathrm{g}^{-1} T$. harzianum was the average of the five readings. The experiment was repeated at different incubation times of $4,8,12,24$, and $48 \mathrm{~h}$. The stability of $T$. harzianum in the encapsulated formulation was determined via a similar procedure of conidia release. The incubation time was $24 \mathrm{~h}$, and measurements were made at monthly intervals throughout the 12-month storage period.

\section{Statistical analysis}

The data were analysed using a one-way analysis of variance (ANOVA) with Statistical Analysis Software (S.A.S.) 9.2. The effect of the treatment was considered significant at $P \leq 0.05$. Statistical analyses of $t$-test and $f$-test were applied to determine the significance of the treatment, while the mean comparison was performed according to the least significant difference (LSD) method.

\section{Results}

\section{Physical characterisation of the alginate- montmorillonite-starch}

The physical appearance of the beads prepared with different concentrations of starch as filler in alginatemontmorillonite-starch combination is tabulated in Table 1. Significant differences $(P \leq 0.05)$ in weight and diameter of encapsulated beads and positive correlation $\left(R^{2}=0.95\right)$ were observed with the increased amount of starch from $1 \%$ to $10 \%$. The weight increased from $2.79 \pm 0.10$ to $7.27 \pm 0.25$ $\mathrm{mg}$, while the diameter increased from $1.39 \pm 0.06$ to $1.94 \pm$ $0.03 \mathrm{~mm}$ (Table 1). The sphericity factor (SF) was used to determine the shape of the beads because it can accurately detect the change of the beads. The SF varied from zero (for a perfect sphere) to one (for an elongated structure). Table 1 shows the SF of beads in the range of $0.03 \pm 0.002$ to $0.07 \pm$ 0.009 , indicating that most of the beads are spherical. The best spherical shape is noted in beads with $10 \%$ starch modification.

Similarly, significant differences $(P \leq 0.05)$ in beads shrinkage are noted between alginate-montmorillonitestarch (1\%), alginate-montmorillonite-starch (3\%), and alginate-montmorillonite-starch (10\%) (Table 1). Increasing the starch concentration will affect the shrinkage characteristic, where the level of shrinkage is reduced by $25 \%$. In comparison, the bead swelling for the starch concentration at $1 \%, 3 \%$, and $5 \%$ did not exhibit any statistical differences $(P \leq 0.05)$. However, alginatemontmorillonite-starch (10\%) showed a significant 
Table 1: Comparison of physical appearance, weight, diameter, shrinkage, shape factor, and swelling ability of alginate-montmorillonitestarch beads with varied starch concentrations

\begin{tabular}{|c|c|c|c|c|}
\hline Starch content $(\%)$ & 1 & 3 & 5 & 10 \\
\hline \multicolumn{5}{|l|}{ Physical appearance } \\
\hline Weight (mg) & $2.79 \pm 0.1^{\mathrm{d}}$ & $3.99 \pm 0.04^{\mathrm{c}}$ & $4.47 \pm 0.06^{\mathrm{b}}$ & $7.27 \pm 0.25^{\mathrm{a}}$ \\
\hline Diameter (mm) & $1.39 \pm 0.06^{\mathrm{d}}$ & $1.60 \pm 0.04^{\mathrm{c}}$ & $1.74 \pm 0.02^{\mathrm{b}}$ & $1.94 \pm 0.03^{\mathrm{a}}$ \\
\hline Shrinkage (\%) & $58.31 \pm 1.82^{\mathrm{a}}$ & $47.98 \pm 1.37^{\mathrm{b}}$ & $48.48 \pm 0.55^{\mathrm{b}}$ & $43.30 \pm 1.38^{\mathrm{c}}$ \\
\hline Spherecity factor & $0.07 \pm 0.009^{\mathrm{a}}$ & $0.62 \pm 0.014^{\mathrm{ab}}$ & $0.41 \pm 0.002^{\mathrm{b}}$ & $0.39 \pm 0.002^{\mathrm{b}}$ \\
\hline & $59.31 \pm 5.64^{b}$ & $60.05 \pm 2.02^{b}$ & $62.11 \pm 0.97^{\mathrm{b}}$ & $67.31 \pm 1.9^{\mathrm{a}}$ \\
\hline
\end{tabular}

Values show the means \pm standard error $(\mathrm{n}=5)$. Data with different letters $(\mathrm{a}-\mathrm{d})$ in a row are significantly different at $P \leq 0.05$ using LSD

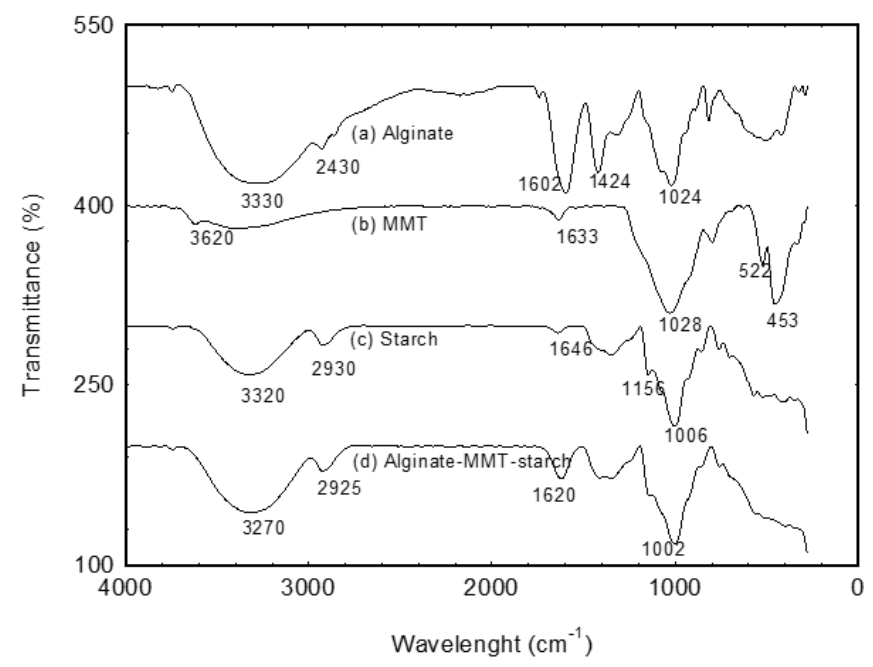

Fig. 1: FTIR spectrum of (a) alginate; (b) montmorillonite; (c) starch and (d) alginate- montmorillonite-starch. The shifting characteristic peaks of alginate and starch in the alginate- montmorillonite-starch confirm the interaction between functional groups

difference $(P \leq 0.05)$ than other treatments, with the swelling ability increasing by approximately $8 \%$ (Table 1 ).

\section{Chemical characterisation of alginate-montmorillonite- starch}

The FTIR study revealed a broad band spectrum for all samples in the region between 3270 and $3330 \mathrm{~cm}^{-1}$ attributed to the $\mathrm{O}-\mathrm{H}$ stretching of water molecules. Alginate characteristic peaks at bands 1602 and $1424 \mathrm{~cm}^{-1}$ refer to the asymmetric and symmetric $\mathrm{COO}^{-}$stretching, while the peak at $1024 \mathrm{~cm}^{-1}$ is attributed to the $\mathrm{C}-\mathrm{O}-\mathrm{C}$ stretching (Fig. 1). The characteristic montmorillonite peaks observed at $3620 \mathrm{~cm}^{-1}$ is attributed to the $\mathrm{Si}-\mathrm{OH}$ stretching, while the following peak at $1633 \mathrm{~cm}^{-1}$ is of the $\mathrm{OH}$ bending of water molecules. The peak observed at $1028 \mathrm{~cm}^{-1}$ is attributed to the $\mathrm{Si}-\mathrm{O}-\mathrm{Si}$ stretching, while the $\mathrm{Si}-\mathrm{O}$ bending vibrations are seen at 522 and $453 \mathrm{~cm}^{-1}$. The characteristic peak for starch observed at $2930 \mathrm{~cm}^{-1}$ is attributed to the C$\mathrm{H}$ stretching. Meanwhile, the peaks observed at 1156 and $1006 \mathrm{~cm}^{-1}$ represent the $\mathrm{C}-\mathrm{O}$ and $\mathrm{C}-\mathrm{C}$ stretching of the starch polymer glucose unit.
The internal morphological structure of alginate has a uniform interpenetrating alginate linkage, which is dense and packed (Fig. 2a). Montmorillonite has an irregular plate-like pattern of hundreds of micrometres in twodimension, length, and width (Fig. 2b), while starch shows round polygonal shapes sized at $12.93 \mu \mathrm{m}$ (Fig. 2c). The surface area of starch is $0.014 \mathrm{~m}^{2} \mathrm{~g}^{-1}$, with a pore diameter of $2588 \AA$, while the montmorillonite surface area is 227.56 $\mathrm{m}^{2} \mathrm{~g}^{-1}$, with a pore diameter of $60.68 \AA$. Although no surface area was recorded for alginate due to the hydrogel linkage, it has a pore diameter of $175.24 \AA$. The morphology of alginate-montmorillonite-starch beads showed a homogenous distribution of starch particles in the matrix (Fig. 2d), with the surface area and pore diameter of 4.462 $\mathrm{m}^{2} \mathrm{~g}^{-1}$ and $43.27 \AA$ A.

The X-ray diffraction analyses of alginate, montmorillonite, starch, and alginate-montmorillonitestarchare shown in Fig. 3. The characteristic sharp peak of montmorillonite at $2 \theta$ of $8.8^{\circ}$ corresponded to a $d$-spacing value of $5.04 \AA$. The interlayer spacing of the montmorillonite structure is in the diffraction range between $2^{\circ}$ and $10^{\circ}$. Meanwhile, the $d$-spacing value of starch is 2.96 
Table 2: Comparison of entrapped T. harzianum conidia in alginate-montmorillonite-starch beads with different concentration of starch before and after drying process

\begin{tabular}{lllll}
\hline Alginate $(\% \mathrm{w} / \mathrm{v})$ & Montmorillonite $(\% \mathrm{w} / \mathrm{v})$ & Starch $(\% \mathrm{w} / \mathrm{v})$ & Before drying $\left(\log \mathrm{CFU} \mathrm{g}{ }^{-1}\right)$ & After drying $\left(\log \mathrm{CFU} \mathrm{g}^{-1}\right)$ \\
\hline 2 & 1 & 1 & $5.49 \pm 0.06^{\mathrm{dA}}$ & $4.42 \pm 0.27^{\mathrm{bB}}$ \\
2 & 1 & 3 & $5.86 \pm 0.04^{\mathrm{CA}}$ & $4.64 \pm 0.16^{\mathrm{bB}}$ \\
2 & 1 & 5 & $6.18 \pm 0.06^{\mathrm{BA}}$ & $5.36 \pm 0.03^{\mathrm{aB}}$ \\
2 & 1 & 10 & $6.35 \pm 0.05^{\mathrm{aA}}$ & $5.42 \pm 0.20^{\mathrm{aB}}$ \\
\hline
\end{tabular}

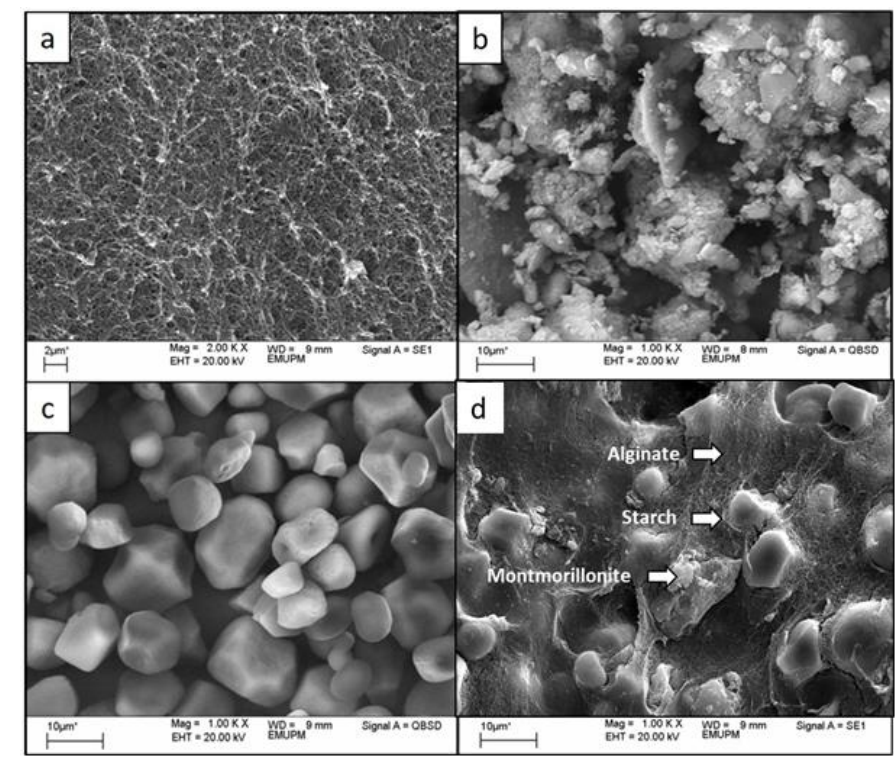

Fig. 2: SEM images of the cross sections of: (a) homogenous interpenetrating of alginate network; (b) irregular plate-like of montmorillonite; (c) starch granules polygonal; and (d) homogenous distribution of montmorillonite and starch in the alginate linkage network of the alginate-montmorillonite-starch beads

$\AA$ at $2 \theta$ of $15.06^{\circ}$. No peak was observed for alginate, confirming that alginate has an amorphous structure. The intensity of the characteristic peak at $2 \theta$ of $17.48^{\circ}$ for starch decreased at $2 \theta$ of $17.56^{\circ}$ for the alginate-montmorillonitestarch mixture. Simultaneously, the intensity peak for montmorillonite at $2 \theta$ of $20.61^{\circ}$ decreased in alginatemontmorillonite-starch at $2 \theta$ of $26.80^{\circ}$.

\section{Viability and stability of encapsulated T. harzianum beads}

The initial concentration of $T$. harzianum conidia in the suspension was $1.3 \times 10^{11} \mathrm{CFU} \mathrm{mL} \mathrm{m}^{-1}$. Significant differences $(P \leq 0.05)$ are observed between the concentrations of entrapped conidia of fresh beads when the starch percentage increases from $1 \%$ to $10 \%$ (Table 2). Conidia entrapped in fresh beads increased from $5.49 \pm 0.06$ to $6.35 \pm 0.05 \log$ $\mathrm{CFU} \mathrm{g}{ }^{-1}$, and for dry beads, though lower than the fresh beads, they still increased from $4.42 \pm 0.06$ to $5.42 \pm 0.06 \mathrm{log}$ $\mathrm{CFU} \mathrm{g}{ }^{-1}$, with increasing concentration of starch.

The SEM image of the cross-section of trapped $T$. harzianum in encapsulated beads (Fig. 4) shows the distribution of T. harzianum conidia throughout the matrix, whereby the average size of conidia is $2.59 \mu \mathrm{m}$. Conidial release of encapsulated T. harzianum beads as a function of time at a different percentage of starch content is elucidated in Fig. 5. No significant difference $(P \leq 0.05)$ is noted in conidia release with increased starch concentration. The maximum release of conidia from alginate-montmorillonitestarch beads is $9.2 \log \mathrm{CFU} \mathrm{g}{ }^{-1}$ at $10 \%$ starch concentration. However, the release is increased with time. Positive correlations $\left(\mathrm{R}^{2}=0.84-0.86\right)$ are observed between conidia release and time, irrespective of starch percentage (Fig. 5). Next, the viability of encapsulated T. harzianum in alginatemontmorillonite-starch $(10 \%)$ in different storage conditions is shown in Fig. 6. The initial CFU is recorded at $8.37 \pm 0.08$ $\log \mathrm{CFU} \mathrm{g}{ }^{-1}$. The results revealed significant variation $(P \leq$ 0.05 ) in the viability of $T$. harzianum encapsulated beads at low temperature than those stored at room temperature. At room temperature $\left(28^{\circ} \mathrm{C} \pm 2^{\circ} \mathrm{C}\right)$, the viability of $T$. harzianum gradually decreased from $7.58 \pm 0.15$ to $6.81 \pm$ $0.27 \log \mathrm{CFUg}^{-1}$ within the first three months and further decreased to $3.23 \pm 0.39 \log \mathrm{CFU} \mathrm{g} \mathrm{g}^{-1}$ in the fourth month. No recovery of $T$. harzianum is noted from the fifth month onwards. On the other hand, the viability of $T$. harzianum beads stored ata cold temperature $\left(5^{\circ} \mathrm{C}\right)$ showed a slow and steady decline in CFU throughout the 12-month storage. The viable count ranged between $8.27 \pm 0.18$ and $1.55 \pm 0.1 \log$ 
Adzmi et al. / Intl J Agric Biol, Vol 26, No 1, 2021

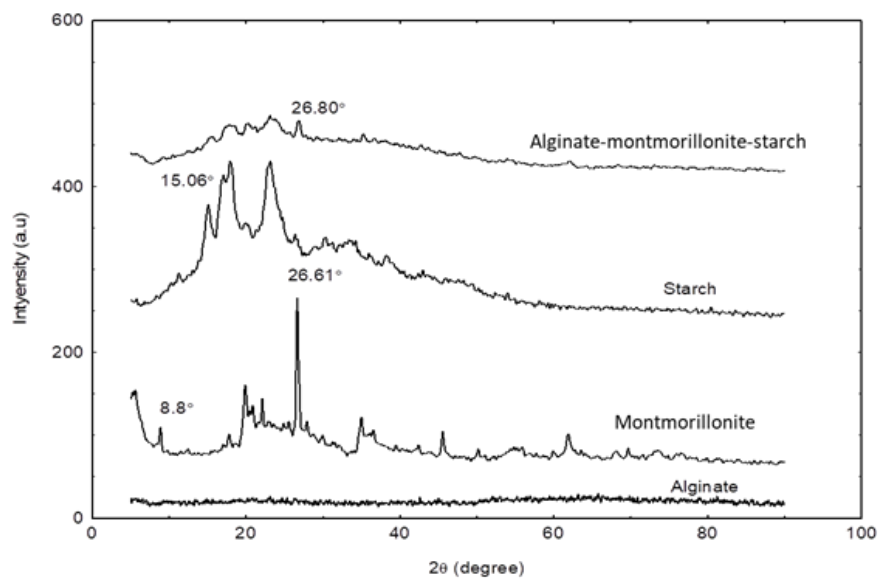

Fig. 3: XRD of alginate, montmorillonite, starch, and alginate-montmorillonite-starch
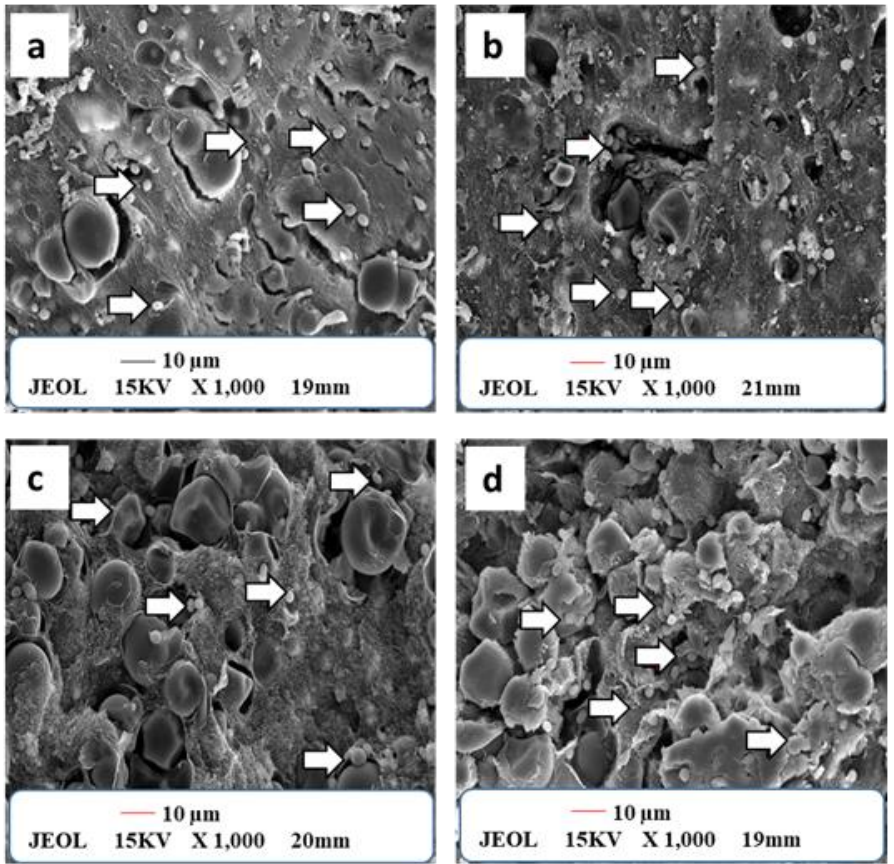

Fig. 4: SEM of the cross-section T. harzianum beads varied by different percentage of starch content; a) $1 \%$ starch; b) $3 \%$ starch; c) $5 \%$ starch; and d) $10 \%$ starch. Arrow showing the distribution of T. harzianum conidia throughout the alginate-montmorillonite-starch matrix

CFU $\mathrm{g}^{-1}$. Thus, at low temperature, T. harzianum beads can be stored up to seven months, with an effective threshold value of $6.59 \pm 0.12 \log \mathrm{CFU} \mathrm{g}^{-1}$.

\section{Discussion}

In this study, T. harzianum was successfully encapsulated in the formulation of alginate, montmorillonite, and starch combination. The formulation was developed with a fixed amount of alginate $(2 \%)$ and montmorillonite $(1 \%)$ but a varied percentage of starch (1\% to $10 \%)$. The physical appearance of the beads produced for all formulations was uniform with a smooth surface. This could be due to the releasing factors of BCAs, as reported in a previous study, where the smooth surface facilitated the permeation of water into the bead matrix, releasing BCAs (Mithilesh and Ree 2012). The increased percentage of starch decreased the percentage of shrinkage. The reduction led to the assumption that the bigger the average sizes of the starch granule, the lower the total shrinkage percentage (Ramdhan et al. 2020). The swelling ability of the beads is an important factor in releasing entrapped conidia. In this study, the swelling ability was increased upon increased starch percentage. These findings could be explained by the initial increase in swelling due to the hydrophilicity of starch, which increased the hydrophilic nature of the beads' chemical formulation (Fernandes et al. 2019). Bead swelling is directly related to the osmotic pressure that 

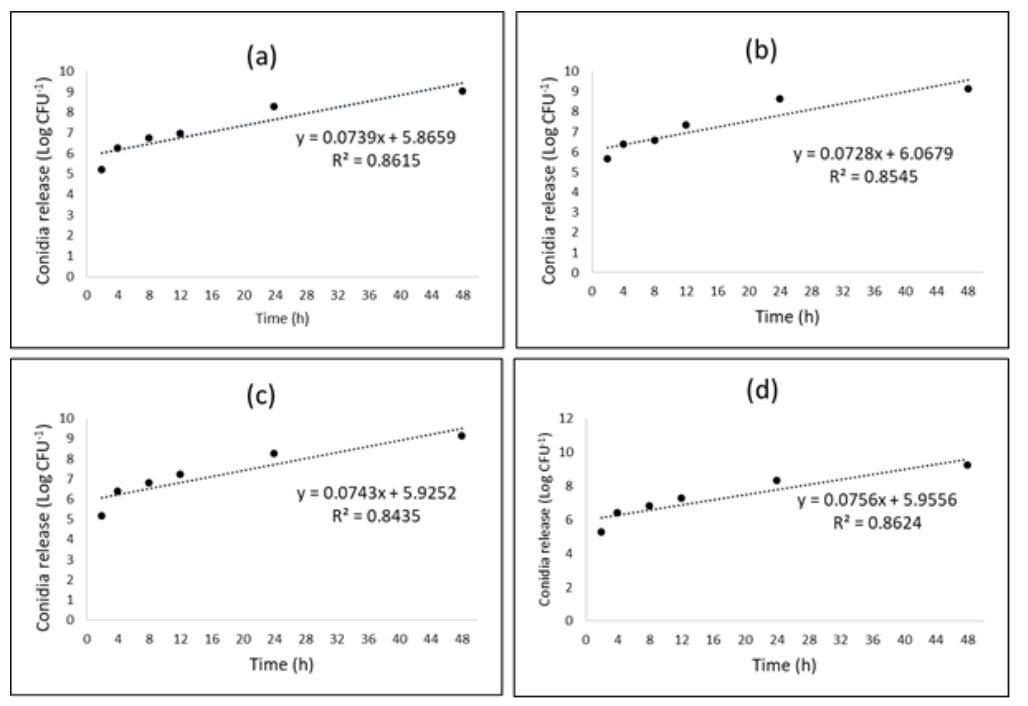

Fig. 5: Conidia release of encapsulated T. harzianum beads as function of time at different percentage of starch content: a) $1 \%$ starch; b) $3 \%$ starch; c) $5 \%$ starch; and d) $10 \%$ starch

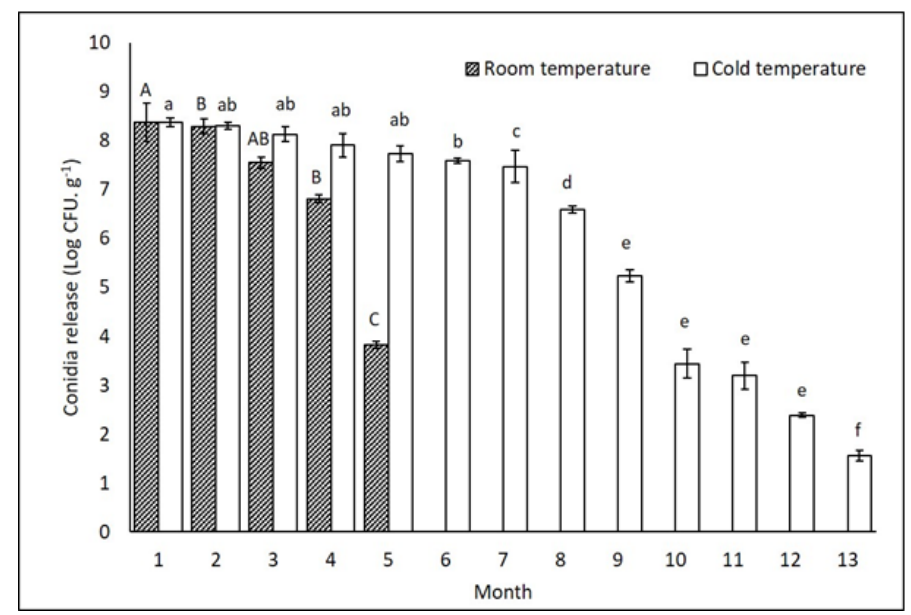

Fig. 6: Comparison between the viability of $T$. harzianum released from the encapsulated beads under different storage conditions (room temperature $\left[28^{\circ} \mathrm{C} \pm 2^{\circ} \mathrm{C}\right]$ and cold temperature $\left.\left[5^{\circ} \mathrm{C} \pm 2^{\circ} \mathrm{C}\right]\right)$ throughout the 12 months storage. Bars indicate standard error and values are mean of five replicates $(n=5)$. (A-C) correspond to the values for cold storage conditions for the time intervals while (a-f) correspond to the values for room storage conditions for the time intervals

occurs by the degree of water absorption. The beads' swelling ratio can be controlled by adjusting their chemical composition (Roy et al. 2009). It was established that adding starch into the formulation could enhance the swelling capacity of the bead. The addition of starch to the matrix as filler enhances the bead swelling ability, which is advantageous for the controlled release of the active agent when the polymer system meets a compatible solvent or fluid in the environment (Wu et al. 2014). Controlled release formulations are better than rapid release formulations because they do not require multiple applications and can reduce the production cost while improving the microbial viability for effective disease control (Caldwell et al. 2012).

Chemical characterisation via FTIR for the alginate- montmorillonite-starch formulation showed the interaction between the functional groups, i.e., the shift of the peak characteristic of $\mathrm{COO}^{-}$stretching for alginate from 1602 to $1620 \mathrm{~cm}^{-1}$. This result indicates that the electrostatic interaction of the carbonyl group reduced the interaction of hydrogen bonding. Concurrently, stronger ionic interaction between carboxylate ions caused free delocalisation of electrons (Asadi-Korayem et al. 2021). Meanwhile, the peak for the $\mathrm{Si}-\mathrm{OH}$ group of montmorillonites at $522 \mathrm{~cm}^{-1}$ disappeared. The findings revealed the interaction of montmorillonite in the alginate-montmorillonite-starch, represented by the formation of hydrogen bonding between the silanol groups on the surface of montmorillonite (He et al. 2019). The interaction from starch in the alginatemontmorillonite-starch bead was observed by the shift in the 
characteristic peak of C-H stretching from 2930 to 2924 $\mathrm{cm}^{-1}$ and $\mathrm{C}-\mathrm{O}-\mathrm{C}$ stretching from 1006 to $1002 \mathrm{~cm}^{-1}$ (Fig. 1). The interaction, which was also revealed on the XRD analysis, indicated that exfoliation occurred when the starch molecules and montmorillonite particles had dispersed in the alginate hydrogel networks (Almasi et al. 2010).

This study also revealed that fewer conidia were entrapped in the dried beads than the fresh ones. The difference between the entrapped conidia before and after drying, could be attributed to the decreased shrinkage percentage of the beads, as portrayed in this study. A high shrinkage percentage would have caused more physical stress to the conidia during the drying process. The montmorillonite particles would have been involved in building up the matrix to prevent the loss of $T$. harzianum conidia. The addition of starch filler may have caused the beads' internal structure to become more porous due to the distribution of the microparticles that occupied the spaces between the alginate and the montmorillonite (Thakur et al. 2016). Simultaneously, starch offers physical protection alteration in the beads matrix by shielding entrapped conidia released during the drying process (Zohar-Perez et al. 2004).

It was reported that the formulation of $\mathrm{BCAs}$ required conidia release from the beads to be conducted in a controlled and sustained manner to survive longer in the environment (Campos et al. 2014). The release mechanism of encapsulated conidia involved two processes; i) the penetration of molecules water into the beads matrix, followed by ii) the swelling of the beads caused by different osmotic pressure inside and outside (Jurić et al. 2019). Several studies reported that the storage condition has a significant impact on the viability and stability of encapsulated cells (Locatelli et al. 2008). The viability of $6.00 \log \mathrm{CFU} \mathrm{\textrm {g } ^ { - 1 }}$ is considered as the limit for biological control agent to remain effective (Larena et al. 2003). This study found that low-temperature storage provided better stability of the encapsulated T. harzianum beads. The number of viability conidia maintained at $10^{6} \mathrm{CFU} \mathrm{g^{-1 }}$ after 7 months of storage at $4^{\circ} \mathrm{C}$. At low temperature, various chemical reactions are suppressed, and the metabolic activity of the encapsulated T. harzianum may occur at a lower rate. In contrast, room temperature storage $\left(28^{\circ} \mathrm{C} \pm 2^{\circ} \mathrm{C}\right)$ may expose the encapsulated $T$. harzianum to stress tolerance responses (Martin et al. 2013). The high-temperature storage showed lower cell stability, which could be due to various biochemical reactions, such as lipid oxidation and accelerated enzymatic reactions ( $\mathrm{Li}$ et al. 2019). Moreover, oxygen was speculated to cause oxidation reactions, which could cause protein denaturation and phospholipid degradation of the dried biological materials (Przyklenk et al. 2017). Incorporating starch into the formulation will produce less porous and less hygroscopic beads, resulting in higher viability and stability upon the storage period (Chan et al. 2011b).

\section{Conclusion}

The combination of starch and montmorillonite as a filler changed the physical properties of the beads. FTIR analysis showed strong interactions between the functional groups of alginates, montmorillonite, and starch. The XRD analysis revealed the exfoliation of starch and montmorillonite in alginate hydrogel. The SEM analysis showed the homogenous distribution of the polygonal particles of starch throughout the alginate-montmorillonite-starch matrix. The T. harzianum beads could maintain the viability of $10^{6} \mathrm{log}$ $\mathrm{CFU} \mathrm{g}{ }^{-1}$ up to 7 months when stored at $5^{\circ} \mathrm{C}$. Overall, the current study proposes the use of a combination of alginate, montmorillonite, and starch as a suitable matrix to encapsulate $T$. harzianum, suggesting a novel means of formulating BCAs. This encapsulation technique can be used for the storage, delivery, and practical applications of other BCAs.

\section{Acknowledgements}

This research was supported by a grant from the Ministry of Energy, Science, Technology, Environment and Climate Change Malaysia and was administered through Research and Development MESTECC Grant (02-01-04-SF2441).

\section{Author Contributions}

FA was involved in designing the work, drafting, writing, analysis, and interpretation of data. MHM, WMY, HAH, AA and RA contributed by interpreting the data, while YS contributed by planning the experiment and statistical analyses.

\section{Conflict of Interest}

The authors declare that they have no conflict of interest.

\section{Data Availability}

The data will be made available on acceptable request to the corresponding author.

\section{Ethics Approval}

No human and/or animal were used as research subject during this study.

\section{References}

Ali A, A Javaid, A Shoaib, IH Khan (2020). Effect of soil amendment with Chenopodium album dry biomass and two Trichoderma species on growth of chickpea var. Noor 2009 in Sclerotium rolfsii contaminated soil. Egypt J Biol Pest Cont 30:1-9

Almasi H, B Ghanbarzadeh, AA Entezami (2010). Physicochemical properties of starch-CMC-nanoclay biodegradable films. Intl J Biol Macromol 46:1-5 
Asadi-Korayem M, M Akbari-Taemeh, F Mohammadian-Sabet, A Shayesteh, H Daemi (2021). How does counter-cation substituition influence inter-and intramolecular hydrogen bonding and electrospinn ability of alginates. Intl J Biol Macromol 171:234-241

Bokkhim H, N Bansal, L Grøndahl, B Bhandari (2016). Characterization of alginate-lactoferrin beads prepared by extrusion gelation method. Food Hydrocoll 53:270-276

Caldwell CJ, RK Hynes, SM Boyetchko, DR Korber (2012). Colonization and bioherbicidal activity on green foxtail by Psuedomonas flourescens BRG100 in a pesta formulation. Can J Microbiol 58:19

Campos EVR, JLD Oliveira, LF Fraceto (2014). Applications of controlled release systems for fungicides, herbicides, acaricides, nutrients, and plant growth hormones: a review. Adv Sci Eng Med 6:373-387

Chan ES, SL Wong, PP Lee, JS Lee, TB Ti, Z Zhang, D Poncelet, P Ravindra, SH Phan, ZH Yim (2011a). Effects of starch filler on the physical properties of lyophilised calcium-alginate beads and the viability of encapsulated cells. Carbohydr Polym 83:225-232

Chan ES, TK Lim, WP Voo, R Pogaku, BT Tey, Z Zhang (2011b). Effect of formulation of alginate beads on their mechanical behaviour and stiffness. Particuology 9:228-234

Chevillard A, H Angellier-Coussy, V Guillard, N Gontard, E Gastaldi (2012). Controlling pesticide release via structuring agropolymer and nanoclays based materials. $J$ Hazard Mater 250:32-39

Curtis FD, G Lima, D Vitullo, VD Cicco (2010). Biocontrol of Rhizoctonia solani and Sclerotium rolfsii on tomato by delivering antagonistic bacteria through a drip irrigation system. Crop Prot 29:663-670

Dai A, Y Liu, B Ju, Y Tian (2019). Preparation of thermoresponsive alginate/starch ether composite hydrogel and its application to the removal of $\mathrm{Cu}$ (II) from aqueous solution. Bioresour Tecnhol 294; Article 122192

Fernandes RS, FN Tanaka, MRD Moura, MF Aouada (2019). Development of alginate/starch-based hydrogels crosslinked with different ions: Hydrophilic, kinetic and spectroscopic properties. Mater Today Commun 21; Article 100636

Fernandez-Perez M, F Flores-cèspedes, E Gonzáles-Pradas, M VillafrancaSánchez, S Pèrez-Garcia, FJ Garido-Harrera (2004). Use of activated bentonites in controlled release formulation of atrazine. J Agric Food Chem 52:3888-3893

He F, Q Zhou, L Wang, G Yu, J Li, Y Feng (2019). Fabrication of a sustained release delivery system for pesticides using interpenetrating polyacrylamide/alginate/montmorillonite nanocomposites hydrogels. Appl Clay Sci 183: 105347

He Y, Z Wu, L Tu, G Zhang, C Li (2015). Encapsulation and characterization of slow release microbial fertilizer from the composite of bentonite and alginate. Appl Clay Sci 109-110:6875

Itadani A, M Tanaka, T Abe, H Taguchi, M Nagao (2007). Al-pillared montmorillonite clay minerals: Low-pressure $\mathrm{CO}$ adsorption at room temperature. J Colloid Interf Sci 313:747-750

Javaid A, A Ali, A Shoaib, IH Khan (2021). Alleviating stress of Sclertium rolfsii on growth of chickpea var. Bhakkar-2011 by Trichoderma harzianum and T. viride. J Anim Plant Sci 31:(In press)

Jurić S, E Đermić, S Topolovec-Pintarić, M Bedek, M Vinceković (2019). Physicochemical properties and release characteristics of calcium alginate microspheres loaded with Trichoderma viride spores. $J$ Integr Agric 18:2534-2548

Khan IH, A Javaid, D Ahmed (2021). Trichoderma viride controls Macrophomina phaseolina through its DNA disintegration and production of antifungal compounds. Intl J Agric Biol 25:888894

Kumar S, M Nehra, N Dilbaghi, G Marrazza, AA Hassan, KH Kim (2019). Nano-based smart pesticide formulation: emerging opportunities for agriculture. J Cont Rel 294:131-153

Larena I, P Sabuquillo, P Melgarejo, AD Cal (2003). Biocontrol of Fusarium and Verticillium wilt of tomato by Penicilliumoxalicum under greenhouse and field conditions. J Phytopathol 151:507-512

Lecomte C, C Alabouvette, V Edel-Hermann, F Robert, C Steinberg (2016). Biological control of ornamental plant disease caused by Fusarium oxysporum: A review. Biol Cont 101: 17-30
Li W, L Liu, H Tian, X Luo, S Liu (2019). Encapsulation of Lactobacillus plantarum in cellulose based microgel with controlled release behaviour and increase long-term storage stability. Carbohydr Polym 223; Article 115065

Locatelli GO, GFD Santos, PS Botelho, CCL Finkler, LA Bueno (2018). Development of Trichoderma sp. Formulation in encapsulated granules (CG) and evaluation of conidia shelf-life. Biol Contr $117: 21-29$

Ma X, X Wang, J Chen, XN Xuexin, YY Zhoa, W Wang (2015). Microencapsulation of Bacillus subtilis B99-2 and its biocontrol efficiency against Rhizoctonia solani in tomato. Biol Cont 90:34 41

Martin MJ, F Lara-Villoslada, MA Ruiz, ME Morales (2013). Effect of unmodified starch on viability of alginate-encapsulated Lactobacillusfermentum CECT5716. LWT Food Sci Technol 53:480486

Mithilesh Y, KY Rhee (2012). Superabsorbent nanocomposites (alginate-gPAMPS/MMT): Synthesis, characterization and swelling behaviour. Carbohydr Polym 90:165-173

Mohammadi M, MK Heshmadi, K Sarabandi, M Fathi, LT Lim (2019). Hamishehkar, H. Activated alginate-montmorillonite beads as an efficient carrier for pectinase immobilization. Intl J Biol Macromol 137:253-260

Pawar RR, P Lalhmunsiama, SY Gupta, B Sawant, SM Shahmoradi, SM Lee (2018). Porous synthetic hectorite clay-alginate composite beads for effective adsorption of methylene blue dye from aqueous solution. Intl J Biol Macromol 114:1315-1324

Przyklenk M, M Vemmer, M Hanitzsch, A Patel (2017). A bioencapsulation and drying method increases shelf life and efficacy of Metarhizium brunneum conidia. J Microencapsul 34:498-512

Raha A, S Bhattacharjee, P Mukherjee, M Paul, A Bagchi (2018). Design and characterization of ibuprofen loaded alginate microspheres prepared by ionic gelation method. Intl J Pharm 6:2713-2716

Ramdhan T, SH Ching, S Prakash, B Bhandari (2020). Physical and mechanical properties of alginate based composite gels. Trends Food Sci Technol 106:150-159

Rathore S, PM Desai, CV Liew, LW Chan, DWS Heng (2013). Microencapsulation of microbial cells. J Food Eng 116:369-381

Riyajan SD (2017). Physical property testing of a novel hybrid natural rubber-graft- cassava starch/sodium alginate bead for encapsulating herbicide. Polym Test 58:300-307

Rodrigues FJ, MF Cedran, JL Bicas, HH Sato (2020). Encapsulated probiotic cells: Relevent techniques, natural sources as encapsulating materials and food applications - A narrative review. Food Res Intl 137:1-16

Roy A, J Bajpai, AK Bajpai (2009). Dynamics of controlled release of chlorpyrifos from swelling and eroding biopolymeric microspheres of calcium alginate and starch. Carbohydr Polym 76:222-231

Schoebitz M, H Simonin, D Poncelet (2012). Starch filler and osmoprotectant improve the survival of rhizobacteria in dried alginate beads. J Microencapsul 29:532-538

Simó G, E Fernández- Fernández, J Villa-Crespo, V Ruipérez, JM Rodríguez-Nagolas (2017). Research progress in coating techniques of alginate gel polymer for cell encapsulation. Carbohydr Polym 170:1-14

Singh B, DK Sharma, R Kumar, A Gupta (2009). Controlled release of the fungicide tiram from alginate-starch-clay based formulation. Appl Clay Sci 45:76-82

Soresh M, GE Harman (2008). The relationship between increased growth and resistance induced in plants by root colonizing microbes. Plant Signal Behav 3:237-239

Sriamornsak P, J Nanthanid, M Luangtana-anan, S Puttipipatkhachorn (2017). Alginate-based pellets prepared by extrusion/spheronization: A preliminary study on the effect of additive in granulating liquid. Eur J Pharm Biopharm 67:227-235

Szczech M, R Maciorowski (2016). Microencapsulation technique with organic additives for biocontrol agents. J Hortic Res 24:111-112

Tam SK, J Dusseault, S Bilodeau, JP Langlois (2011). Yahlia, L. Factors influencing alginate gel biocompatibility. $J$ Biomed Mater Res A 98:40-52 
Tavassoli-Kafrani E, H Shekarchizadeh, M Masoudpour-Behabadi (2016). Development of edible films and coatings from alginates and carrageenans. Carbohydr Polym 137:360-374

Thakur S, S Pandey, OA Arotiba (2016). Development of sodium alginate-based organic/inorganic superabsorbent composite hydrogel for absorption of methylene blue. Carbohydr Polym 153:34-46

Vemmer M, AV Patel (2013). Review of encapsulation methods suitable for microbial biological control agents. Biol Cont 67:380-389
Wijesinghe CJ, RW Wijeratnam, JKRR Samarasekara, RLC Wijesundera (2011). Development of a formulation of Trichoderma asperellum to control black rot disease on pineapple caused by Thielaviopsis paradoxa. Crop Prot 30:300-306

Wu Z, Y He, L Chen, Y Han, C Li (2014). Characterization of Raoultella planticola Rs-2 microcapsule prepared with a blend of alginate and starch and its release behaviour. Carbohydr Polym 110:259-267

Zohar-Perez C, I Chet, A Nussinovitch (2004). Irregular textural features of dried alginate-filler beads. Food Hydrocoll 18:249-258 